\section{The temporal enigma, again}

Huw Price

The Mind of God: The Scientific Basis for a Rational World. By Paul Davies. Simon and Schuster: 1992. Pp. 254. $\$ 22, £ 16.99$.

The Matter Myth: Dramatic Discoveries that Challenge our Understanding of Physical Reality. By Paul Davies and John Gribbin. Simon and Schuster Viking: 1992. Pp. 320. \$12 (pbk), $£ 16.99$ (hbk).

The Mind's Sky: Human Intelligence in a Cosmic Context. By Timothy Ferris. Bantam: 1992. Pp. 281. \$22.50 £16.99.

The Capricious Cosmos: Universe Beyond Law. By Joe Rosen. Macmillan, Inc. (USA): 1992. Pp. 224. \$19.95.

PAUL Davies presents us with a temporal enigma. Twenty books in as many years, a successful career as a 'serious' physicist, and a very active round of broadcasts and public lectures - how on earth does he find the time? Whatever his secret, it works as well in Australia as it used to in the United Kingdom. Davies has become a frequent contributor to the scientific side of Australian cultural life in the past couple of years, and a very popular one: his most recent public appearance at the University of Sydney filled three or four large lecture theatres.

In his twentieth book, The Mind of God, Davies tackles some of the traditional Big Questions that generate this public interest, and some interesting new ones: Can science explain everything? Why is it that science can explain anything, and what does this tell us about our relation to the Universe? Does the existence of the Universe need any external cause or creator? Could it have been otherwise? Is it a giant computer? It is not easy to write intelligently and accessibly about issues at this level, but Davies here does it exceptionally well. As a whole, the book is an impressive and rather moving reflection on physics, humanity and the Universe, as it appears to one of the discipline's most able communicators towards the end of the twentieth century.

Let me mention three points of detail that left me unsatisfied. First, the suggestion that physical systems might be computers calculating their own behaviour seems uncomfortably close to the idea that the world is a language describing its own state (as it would be for the professors of Swift's Academy of Lagado, for example, who proposed eliminating words in favour of the things themselves). Does the Solar System

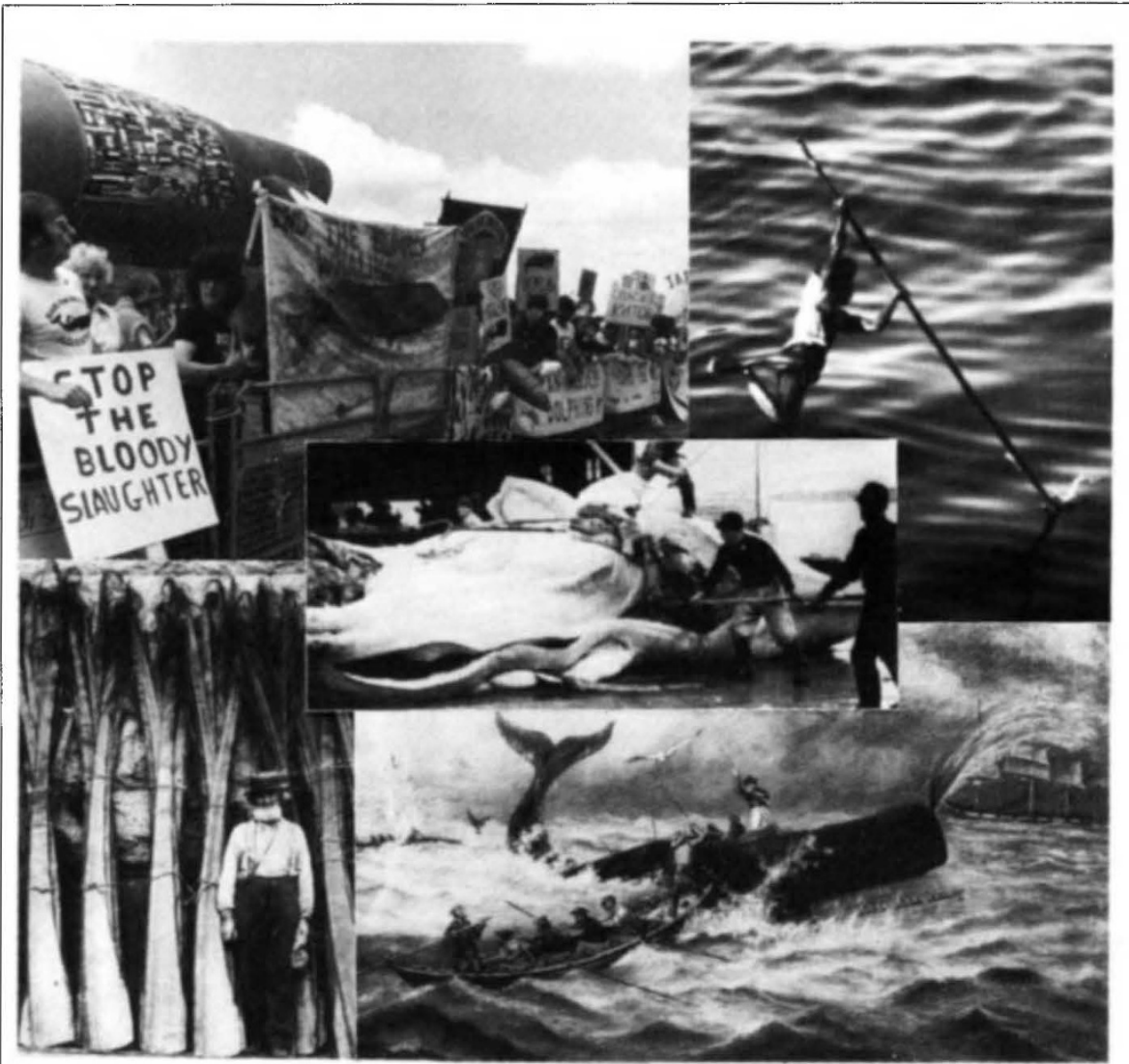

Humans have hunted whales for around a thousand years, killing millions of them for their valuable meat, oil and bones. These illustrations are just a sample from the many more that appear in Men and Whales by Richard Ellis (Robert Hale, price £25), the "first comprehensive history of the whale's turbulent — and always controversial — relationship with humankind".

really compute its planetary orbits in any more interesting sense than a cat on a mat describes its own location?

Second, the question of why the Universe is comprehensible at all - why it is not a $P 2 C 2 E$, in Rushdie's useful technical notation* — seems to me more slippery than Davies allows. How do we know that the Universe is significantly comprehensible? What would it look like if it wasn't, by and large? Could we tell?

Third, the book's concern with the question of whether the Universe requires a creator to get it started seems to me a little laboured. Davies describes the Augustinian viewpoint, which neatly sidesteps our usual obsession with beginnings by placing the creator outside time. If modern cosmology tells us anything it is that this is the right move: the idea that the Universe needs to be externally started has no more objective basis than the idea that it needs to be externally stopped. After all, if there were a place for a non-Augustinian creator, there would also be a place for the question of at which end He started: did He create the Universe at the Big Bang and let it run forward, or create it at the Big Crunch and let it run back? Cosmology does not take the latter possibility

* "A Process Too Complicated To Explain"; see Haroun and the Sea of Stories, page 57, Granta, 1990 seriously, and neither should it the former.

Far from detracting from the book, however, points of this kind illustrate one of its virtues. Despite its scope and accessibility, it is sufficiently thorough to permit critical engagement about points of detail. The Mind of God would thus make an excellent basis for an undergraduate philosophy course on Science and the Big Questions, and may also be warmly recommended to the general reader.

I found The Matter Myth less satisfying. Here, Davies and John Gribbin claim to describe a revolutionary change taking place as a result of recent developments in science: the overthrow of materialism, and liberation from the alienation and depersonalization that has so long accompanied it. It turns out that 'recent' is being used rather liberally: two of the key ingredients of this claimed revolution are our old friends relativity and quantum mechanics. It has long been commonplace that relativity views the Universe as a 'static' structure incorporating time, rather than as a dynamic entity changing in time; and that quantum mechanics leads to indeterminism. More importantly, it has long been obvious that there is no comfort for humanism in any of this. Quantum indeterminism does nothing for our free 
will; while what could be more impersonal than the block Universe, in which our entire existence is some almost insignificant thread?

Indeed, it seems to me that the main thesis of The Matter Myth rests on an ambiguity in the notions of materialism and mechanism. These terms are sometimes used in contrast to humanism or idealism, and sometimes with reference to a specific (say, newtonian) conception of the fundamental nature of the world. These two senses are somewhat mixed up when Davies and Gribbin describe mechanism as "the belief that the physical Universe is nothing but a collection of material particles in interaction, a gigantic purposeless machine, of which the human body and brain are unimportant and insignificant parts". Provided that we keep the senses distinct, it is possible to see that a world view may be materialist in the first sense - that is, impersonal - without being newtonian. And that, surely, is what the physics of the past century has given us. (Lest it be suggested that I have ignored genuinely recent developments concerning chaos and nonlinearity, what comfort is it if it turns out that we and our Universe are unpredictable machines? Is a rogue robot any more human than its predictably programmed cousin?)

Leaving aside its claims concerning materialism, there is a lot to recommend the book. Davies and Gribbin are both masters of the art of describing complex scientific ideas to lay audiences, and in this respect they maintain their usual high standards. So read it for this, but take the news of the revolution with a pinch of salt.

One of the great challenges of the popular science genre is to be entertaining as well as intellectually stimulating. A writer who does well in this respect is Timothy Ferris, whose The Mind's Sky is an enjoyable ramble through a variety of topics to do with minds, brains and their place in the cosmos. I particularly liked the suggestion that there might already be a self-extending information network, spreading the accumulated knowledge of diverse civilizations through the galaxy. Let us hope that when we find our local terminal it is in working order. (How frustrating to have to wait 10,000 years for the Repair-Creature.)

By contrast, The Capricious Cosmos is a salutary example of the dangers of venturing into print beyond one's field. The basic guidelines here are those of foreign travel: try to pick up a smattering of the language, and tread lightly. This book is a physicist's journey into metaphysics, but fails on both counts.

Huw Price is in the Department of Traditional and Modern Philosophy, University of Sydney, Sydney, NSW, Australia 2006.

\section{From brilliance to crackpottery}

Ian Stewart

Cosmography: A Posthumous Scenario for the Future of Humanity. By R. Buckminster Fuller (adjuvant: Kiyoshi Kuromiya). Macmillan, Inc. (USA): 1992. Pp. 277. \$24.95.

AT a time when a 60 -atom carbon cage named in honour of an architect has boldly been hailed by Science as "molecule of the year", a book on the working philosophy of the man himself would seem only appropriate. That the molecule should be called "buckminsterfullerene' rather than 'truncatedicosahedrene' reflects the extent to which Buckminster Fuller succeeded in putting his ideas across to humanity. But not every innovation for which he tends to be given credit is as original as his admirers imagine.

In 1983, on the day that Buckminster Fuller died, the manuscript of Cosmography was found stacked in the middle

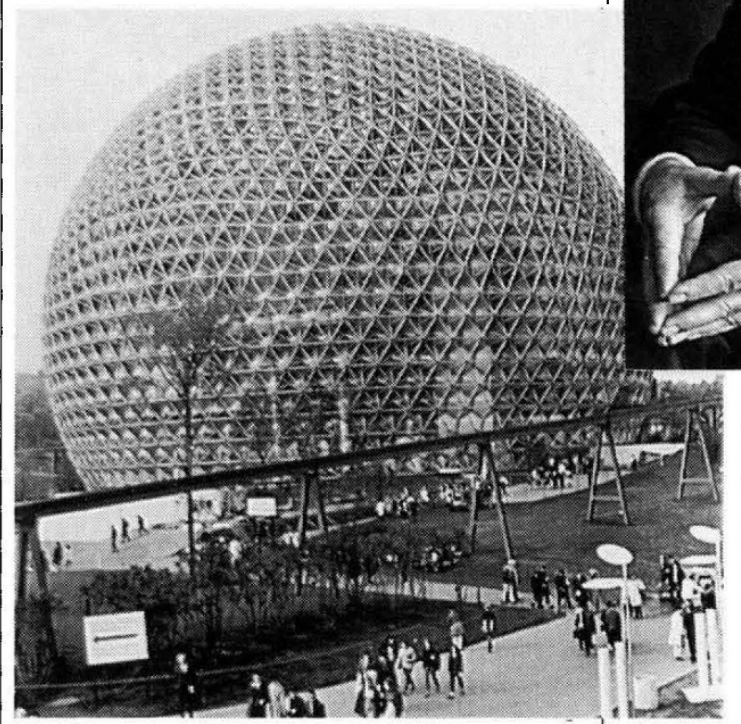

of his desk. Attached to it was a note to his daughter and grandchildren, stressing "the extraordinary importance of my now being written book". Kiyoshi Kuromiya, the "adjuvant", a term that Fuller borrowed from medicine, has sensibly preserved the author's "idiosyncratic concepts, tone, syntax, and phraseology". As a result, we have a book that lets its readers get inside that extraordinary — and rather frustrating — mind.

Fuller saw the human race as still living in the Dark Ages, locked into a futile circle of misinformation, perverted by big business, militarism and organized religion. He sought the rebirth of humanity in a better future, a world in which individual genius would be nurtured rather than suppressed. This philosophy led him to conduct his life as an "experiment in individual initiative". It led to some remarkable achievements, most notably the invention of the geodesic dome. It led him to formulate the idea of "synergetics", in which objects are replaced by systems, balanced between their internal and external features. And it led him to make scathing but rather generalized criticism of conventional science. All of this was laced with a characteristic obsession with numerology and an uncompromising view of the importance of truth.

Cosmography reveals the astonishing strengths of Fuller's mind, as well as its flaws. One cannot doubt the sincerity of his vision of the human predicament, nor

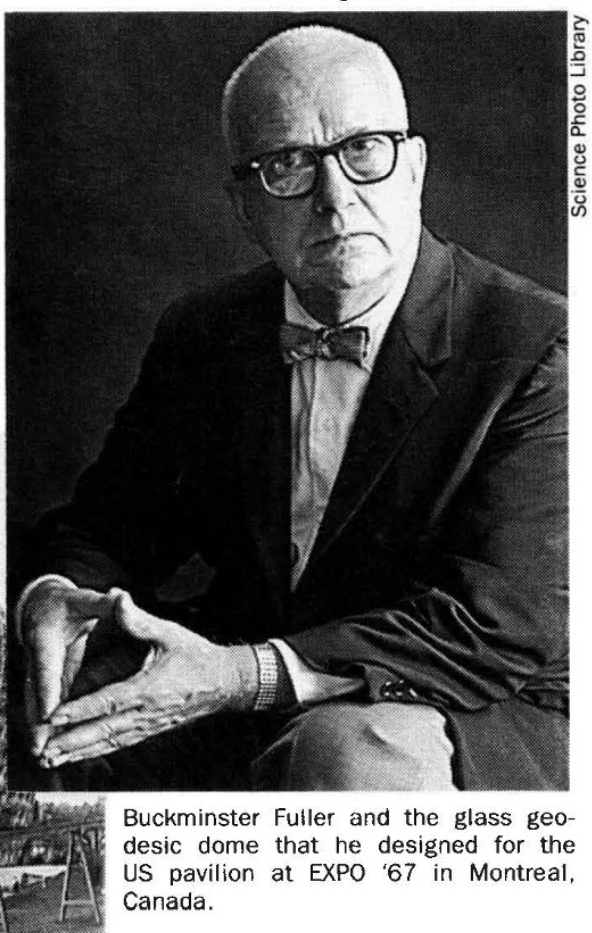
fault many of his insights: "Big money, big religion, and big politics are all still deliberately frustrating human comprehension"; or, as my father once said to me, "they teach you enough to take orders, but not to give them." Equally, it is hard to agree that every child is born a genius. With more than 200,000 geodesic domes in existence, one can hardly quibble over Fuller's success and originality as an architect. But what about his claim that stacks of cubical boxes tend to separate as they grow higher because local verticals are not parallel on a spherical Earth? To Fuller this is important, representing yet another nail in the coffin of the "misinformed XYZ" coordinate system beloved by physicists. To me, and to physicists, it shows that Fuller can't do a back-of-the-envelope calculation. Except that he can - when he wants to. His geometric ingenuity is striking. Who else would have noticed that you can fold up 